\title{
Demystifying Cost Misperception as a Challenge to Green Building Adoption in Nigeria
}

\begin{abstract}
Purpose

Information about the financial implication of green buildings (GB) is laden with cost misperceptions (CM). CM is applied to make adoption decisions without factual clarifications hence, the low adoption of related technologies across the globe. This study explored the causes of CMs among construction stakeholders.
\end{abstract}

\section{Design/methodology/approach}

The research adopted two-tier approaches involving a Delphi study and a questionnaire survey. Twelve GB experts validated the applicability of theoretical drivers of CM to the research setting and their level of influence in stage one. The output of stage one facilitated the development of the research questionnaire administered to 415 construction stakeholders and GB experts in Nigeria. The study analysed data from 254 valid responses using Factor Analysis, Fussy Set Theory, and Kruskal Wallis test to explain the prevalent causes of CMs.

\section{Findings}

The causes of CMs converge towards seven principal factors including low knowledge of GB practices, non-familiarity with performance metrics, inadequate evidence, poor-risk perceptions, and reliance on the costs of exemplar projects. The study explained these results using gaps in cost management, knowledge, and sustainability accounting to show the critical improvements that can improve cost perceptions and GB adoption.

\section{Originality}

The study reveals causes of negative dispositions toward the cost of GB that disrupt the decision to adopt associated technologies.

\section{Practical and theoretical implications}

CMs are not abstract but develop from detectable factors within a specific context. Developing regional practices would enhance the quality of evidence needed to advance factual knowledge of cost in GB development. The important sources of CMs validated in this study are precursors of effective misperception management and enablers of rational decision.

Keywords: adoption, cost management gap, knowledge gap, misperceptions, sustainability accounting

\section{Introduction}

Green Building (GB) establishes sustainable development goals in the construction industry. GB refers to structures created using environmentally friendly and resource-efficient approaches. One of the most effective ways to promote the adoption of GB pivots on lowering their first costs (Bond and Perret, 2012; Abidin and Azizi, 2016). However, the knowledge of the cost of GB is uncertain and linked with various non-factual misperceptions (Kats, 2010; Shi et al., 2016). The term misperception refers to the mental conception and reaction toward information that is both factually incorrect and untrue (Renner et al., 2015). Different reports conceived the cost of GB as 
uncertain and endorsed the term 'misperception' (Shi et al., 2016; World Green Building Trend, WGBT, 2018; Sustainable Building Market Study, SBMS, 2019). The prevalent cost misperception (CM) across settings suggests the cost of GB is significantly higher than the alternate construction approach (Sherwin, 2006; Taemthong and Chaisaard, 2019). Even though GB development has a cost premium, this cost is a marginal increase. Extra expenditure greater than $15 \%$ is a misperception of their true financial implications (Kats, 2010). CMs portray GB as more prohibitive, preventing adoption, and misreads capital cost as the first cost (Sherwin, 2006; SBMS, 2019) and a commodity-related barrier to their adoption (Chau et al., 2013). Stakeholders held to CMs oblivious of their technically non-factual dispositions (Sun et al., 2019), therefore, improving CM is strategic to growing the adoption of GB (Darko et al., 2017).

CMs and the resultant high-cost perceptions are an unwanted dilemma for stakeholders in the decision to adopt GB (Zhou and Lowe, 2003). In Nigeria and other parts of the world, the corollary of high-costs lower the uptake of GB technologies in project development (Fullbrook et al., 2006; Horhota et al., 2014; Ogunba, 2018). High-cost perceptions widen the gap between the desire to adopt and eventual engagement with GB (Tierney and Tennant, 2015). Apathy to risk (Shi et al., 2016), negative impacts on marketability (Choi, 2009), increased complexity, and a long payback period (Choi, 2009) are other promoted effects of CMs in the literature. CMs exist because the data underpinning the cost of GB are defective, provide inadequate evidence (Galupo and Tu, 2010; Fuerst et al., 2015; SBMS, 2019), and poses methodological gaps (Ogunba, 2018; Chegut et al., 2019). The reliance on institutional reports, where data from exemplar projects apply also contribute to cost uncertainties (Langdon, 2007). Amidst inherent $\mathrm{CMs}$, the factual cost information reveal the extra expenditure for ordinary level certification remains an insignificant marginal cost (Langdon, 2007; SBMS, 2019). Therefore, the factual knowledge of its true cost would reinforce the confidence of developers, clients, and financiers (Reichardt, 2014; SBMS, 2019).

Despite the negative consequences of CM in GB adoption, limited expositions exist that account for their causes. This study contributes to knowledge by evaluating why CMs exist. The objective was to evaluate the principal causes of CM. The knowledge of factors driving CMs would engender the validation of their factual positions as a strategy to improving the adoption of GB in Nigeria (Ogunba, 2018; Ekung, 2019). The study introduces a pertinent research problem; since cost-related factors are seminal barriers disrupting the smooth adoption of GB (Darko et al., 2017; Nduka et al., 2019). Moreover, CMs prohibit meaningful knowledge of GB practices and undermines stakeholders' inclination to adopt. This research demystifies CMs from detectable regional patterns that can be understood within a specific context. The research question explored why construction stakeholders in Nigeria hold unsupported beliefs about the cost of GB and why is it difficult to discredit this information?

\section{Literature Review}

\subsection{Cost misperceptions and their factual positions}

Misperceptions are genuine views that are incorrect or contradictory to existing proof in the unrestricted space (Flynn et al., 2017). Byron and Landis (2020) described misperception as variation in the opinions of two persons about a target. In the context of this study, CM is the absence of consensus about the true cost of GB and factually incorrect information of their costs. Several studies and reports acknowledged the existence of CMs and noted their presence disrupts diffused adoption of GB (WGBT, 2018; SBMS, 2019). The understanding of CM in this study grows from the charitable application of the term to describe non-factual beliefs about the cost of 
GB (WGBT, 2018; ARDOR, 2020). According to Kats (2010), a green cost premium greater than $15 \%$ constitutes a misperception of the true cost. The survey of Vietnamese investors, for instance, showed a cost premium of 20\% (ARDOR, 2020). The report of the World Green Building Council (2016) showed varying cost premiums up to 20\%, while unclassified 3-26\% premium was reported for ten simulated retrofits in Auckland (Ade, 2018). Ogunba (2018) reported the possible cost premium of $15 \%$ and above based on qualitative perceptions of stakeholders in Lagos, Nigeria. These studies reported a cost premium greater than $15 \%$ to show that CMs exist in communicating the cost of GB.

Against the reported high-cost premiums, ordinary certification is achievable at zero extra cost (Ekung, 2019; Sun et al., 2019). The costs could be cheaper or equal to the costs of an alternate construction approach (Sherwin, 2006; Mapp et al., 2011; Dobson et al., 2013). Lower cost premium (1-5\%) also exist subject to the level of certification (Kats et al., 2003; Hwang et al., 2017). Langdon (2007) revealed no significant difference exists between the cost of green and non-GB. A study of Israeli GBs also showed that the cost premium is $2 \%$ with benefits that are ten times higher than the extra expenditure (Kats, 2010; Kats, 2014). GB has a lifetime lower capital costs due to reduced operational costs that are lower than conventional buildings (Buys and Hurbissoon, 2011) amidst greater economic performance (Heerwagen, 2000; Carter, 2007). Overall, perceptions of significant high-cost in GB are contestable based on the spectrum of evidence that showed the cost premium is marginal.

\subsection{Theoretical development}

The study conceives that decision-making depends on available information irrespective of its quality. The tendency to improve rational decision-making increases when the information underpinning decision processes are improved. To advance the causes of CM in GB adoption, this study commits to the tenets of decision theory. Fundamentally, decision theory is concerned with how decision-makers arrived at rational decision (Peterson, 2009). Rational decisions refer to goal-directed behaviour in the face of alternatives with varying results obtained using probabilities (Kovach et al., 2015). The rationality in the decision interface is formed by the decision-makers preference factors that determine the action of choice (Rott, 2011). Kovach et al. (2015) outlined decision factors such as moral, social, and ethical issues; the list of factors depends on available information. Decision-makers function within the premise of bounded rationality due to limited information and cognitive issues (Kovach et al., 2015). The choice emerging from bounded rationality is at best, not rational under decision theory, but only shows intentions to be guided by rational parameters (Peterson, 2009).

By extending decision-choice factors to GB adoption, the paper notes that one of the most important decision factors in GB adoption is cost. Stakeholders impose cost as a preference factor in GB adoption beyond intention to be rational (Bond and Parrett, 2012). The pertinent cost information used at the decision interface suggests GB has a significantly higher expenditure than the alternate construction method (Sherwin, 2006; Taemthong and Chaisaard, 2019). This assumption positions GB adoption as a qualified domain that decision theory can apply. Furthermore, GB exists as improved solutions (that is, alternative) to the conventional construction approach; hence, their adoption decision processes operate under rational decision domains (Kovach et al., 2015). However, the decision interface in GB faces the fear of different uncertainties (CMs) hence, their adoption are not strictly rational (Peterson, 2009). Over the years, construction researchers have failed to model the fear that a cluster of factors distorts GB's 
cost information as well as the opportunity to outmaneuver these factors to improve adoption decisions. As a result, stakeholders unknowingly believe CMs are contingent probability factors imperative to the rational decision that must prevent the decision to adopt GB. Building from the prescriptive decision theory (Hastie and Dawes, 2009), the presence of CMs also portray that GB adopters are non-ideal agents with imperfect information (Peterson, 2009; Kovach et al., 2015). This study postulates that improving cost information can improve GB adoption through the knowledge of why CMs exist.

The rational economic decision discourse reviewed above affirmed the existence of imperfect information in the decision processes (Gossner and Steiner, 2018). In this study, we established the causes of distorted cost information in GB development to place the stakeholders in emerging green markets to engage in optimal misperception management. The study contextualise CM using two derivative biases underpinning non-adoption decisions, namely: an illusion of control and an over precision (Steiner and Stewart, 2016). The illusion of control and over precision are contingent biases dealing with overestimation (Gossner and Steiner, 2018), and overvaluation of beliefs (Steiner and Stewart, 2016). Overestimation of GB's cost is not new, for instance, studies reporting 20-35\% cost premium exist (Bartlett and Howard, 2000; WGBC, 2016; Rehm, 2018; ARDOR, 2020). Darko et al. (2017) maintained that the actual budget in GB remains a vastly misperceived context, and parading CM into GB adoption decision processes is an overvalued belief (Zhou and Lowe, 2003; Chau et al., 2013; Horhota et al., 2014; Ogunba, 2018). Decision theory was applied to modelling the challenges facing innovation diffusion in diverse types of conflicts scenarios (Kovach et al., 2015) and climate change (Flynn et al., 2017).

\subsection{Causes of CM and conceptual framework}

Developing from the theoretical and conceptual understanding of CM in the previous sections, this study postulates that CMs are derivatives of cost management, sustainability accounting, and knowledge gaps (Figure 1). Table 1 (SN1-35) shows the variables underlying the three postulated dimensions in the literature. Sustainability accounting gaps (SAG) depict the problem of improper quantification of the various dimensions of greenness to account for the comprehensive details of their financial implications. SAG postulates that suitable quantification of GB and the dissemination of their incidental benefits are objective to reduce misperceptions (Kulczak et al., 2015). SAG further emphaisises the importance of value over affordability in the pursuit of sustainable development (Arvai et al., 2012). This means the importance of pay-off functions (benefits) over the cost of projects is undervalued. Overall, appropriate facts, evidence, information, beliefs, and values are operative to enhance the decision to adopt GB (Arvai et al. 2012; Kulczak et al., 2015).

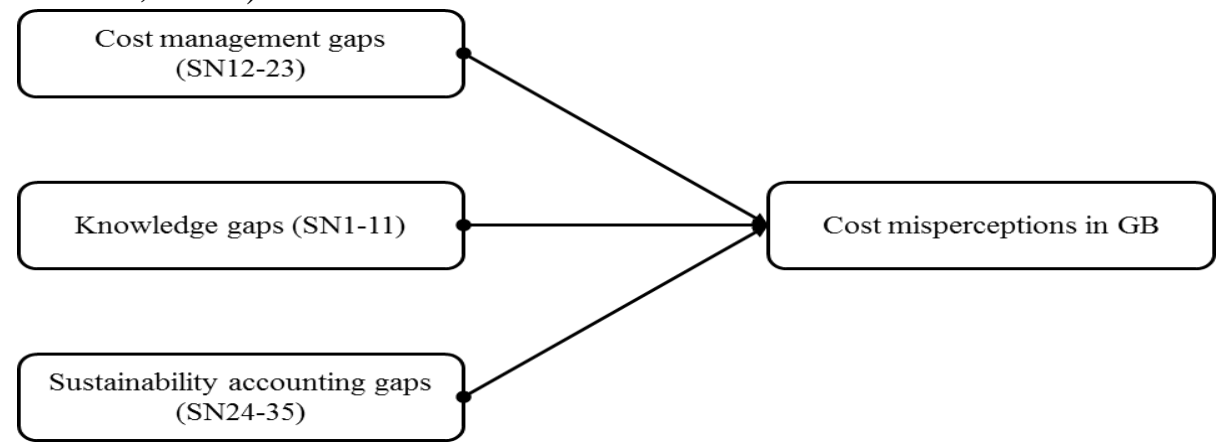

Figure 1: Conceptual framework of causes of CM 
Table 1: Causes of cost misperception in green buildings

\begin{tabular}{|c|c|c|c|}
\hline $\mathbf{S} / \mathbf{N}$ & Categories & Causes of CMs & Sources \\
\hline 1 & Knowledge factors & Low knowledge of GB practices & Gluch et al. (2013) \\
\hline 2 & & Low prioritisation of GB & Gluch et al. (2013) \\
\hline 3 & & Unwillingness to pay a rent for intangible benefits & Lavasani (2018) \\
\hline 4 & & Low education and training & WGBT (2018) \\
\hline 5 & & Skills shortages & WGBT (2018) \\
\hline 6 & & Attitudinal problems (prejudice that cost is high) & WGBT (2018) \\
\hline 7 & & Lack of awareness that cost are reducing & WGBT (2018) \\
\hline 8 & & Secrecy and proprietary nature of costs information & Carter (2007) \\
\hline 9 & & Project characteristics (size, type and location) & Syphers et al. (2003) \\
\hline 10 & & Certification drives cost & Choi (2009) \\
\hline 11 & & Project management factors drives cost & Syphers et al. (2003) \\
\hline 12 & Cost management & Reliance on cost data from oversea literature & Gluch et al., (2013); Ekung (2019) \\
\hline 12 & factors & Inflation of the true cost to address immeasurable risks & Bevan and $\mathrm{Lu}(2013)$ \\
\hline 13 & & Dearth of empirical data & Darko et al., 2020 \\
\hline 14 & & Uncertainty of cost data & Halliday (2008) \\
\hline 15 & & Penchant to historical costs & Halliday (2008) \\
\hline 16 & & Cost data sample biases & Chegut et al. (2019) \\
\hline 17 & & Asymmetric information structure in cost & Bevan and Lu (2013) \\
\hline 18 & & Inability to let-off historical cost & Carter (2007) \\
\hline 19 & & Reliance on costs of exemplar projects & Langdon (2007) \\
\hline 20 & & Lack of and non-application of incentives to discount costs & Langdon (2007) \\
\hline 21 & & Wrong assumptions in sustainability accounting & Syphers et al., (2003) \\
\hline 22 & & Cost-benefits estimating methodological gaps & Ogunba (2018) \\
\hline 23 & & Incongruity in costs data collection & Buys and Hurbissoon (2011) \\
\hline 24 & Sustainability & Poor discounting of costs & Pearce (2008) \\
\hline 25 & accounting factors & Poor costs accounting of benefits and processes & Jerry (2005) \\
\hline 26 & & Low risk perceptions & $\begin{array}{l}\text { Górecki and Díaz-Madroñero } \\
(2020)\end{array}$ \\
\hline 27 & & Increased risk perceptions & Zhou and Lowe (2003) \\
\hline 28 & & Misreading of economic financial benefits & Zhou and Lowe (2003) \\
\hline 29 & & High capital costs & Zhou and Lowe (2003) \\
\hline 30 & & Low market value & Zhou and Lowe (2003) \\
\hline 31 & & Adopting lifecycle costing to account for short-term benefit & Zhou and Lowe (2003) \\
\hline 32 & & Short-termism expectations against long-term value & Häkkinen and Belloni (2011) \\
\hline 33 & & Scope of sustainability features integrated drives extra costs & Gilmour (2013); Ogunba (2018) \\
\hline 34 & & Unfamiliarity with performance metric than costs & Gilmour (2013); Ogunba (2018) \\
\hline 35 & & Sustainability level & Carter (2007) \\
\hline
\end{tabular}

The role of cost management problems in the high-cost of GB is significant. Estimating the cost of GB involves huge data (WGBT, 2018) as well as expertise in innovation in cost management practice (Pearce, 2008). Innovative cost management in GB is a missing link in extant practice and the supporting data is scarce (Ahn et al., 2013). The data needed is termed 'hard data' (SBMS, 2019), and the supply of these data is inadequate to prove the investment in GB is viable (WGBT, 2018). Moreover, hard data have intra and inter-project contexts, but the prevalent data across projects are mainly intra-project, one-dimensional, and unsuitable to advance knowledge (Ahn et al., 2013). The dearth of requisite data and shortage of innovative cost management skills suggest current estimates are plagued with estimation bias (Pearce, 2008).

Knowledge gaps trigger misperceptions that inhibit sustainable development (Hopkins, 2016). However, the pertinent knowledge in the envisaged domain is inadequate or held in breach of coherent understanding of the true practice. For instance, the cost of GB is capital expenditure but misread as the first cost (Darko et al., 2017). The number of stakeholders with no clear understanding of the benefits of GB are enormous and several others are not aware the cost is reducing (Fischer, 2010). The global survey of experienced and non-experienced GB designers 
showed that both groups estimated GB cost premiums within the same margin [18-25\%] (WGBC, 2016). The true knowledge of costs in GB development is either exaggerated or uncertain and asymmetric (Bevan and Lu, 2013; Shi et al., 2016; Ogunba, 2018).

This study evaluated the roles of cost management, sustainability accounting, and knowledge gaps in CMs to fill the literature gap in why the costs of GBs are misread. Table 1 showed the matrix of potential causes of $\mathrm{CMs}$ as precursors of global positions for the study. The understanding suggests these potential $\mathrm{CM}$ drivers can improve to advance rational decisions in GB implementation. However, the empirical standpoint of their relatedness to CM is until date not apparent. This study bridges an empirical gap in the narratives of critical factors underpinning CMs in GB development. Hosseini et al. (2016) showed that the conferment of a critical factor develops from theorization to validation using empirical data analysis. Due to possible variations in the degree of severity of theoretical causes of CMs, the test of consistency in respondents' perceptions was imperative. The study investigated consistency in the perceptions of respondents in different sub-sectors of the sample using a hypothesis test (Ho). The hypothesis (Ho), states that the respondents' perceptions of the causes of CMs do not vary among green building experts, construction professionals, and developers/clients.

\section{Research methodology}

\subsection{Research strategy}

The study implemented a cross-sectional survey using a questionnaire to collect data. The questionnaire measured the respondents' perceptions of the severity of theoretical causes of CMs using an ordinal scale. Thirty-five theoretical variables (Table 1) were ranked on a 5-point Likert scale, where 1-indicated very low and 5-very high impacts. The questionnaire comprised two parts, the first part elicited data on the background information of the respondents, while the second section outlined postulated framings of theoretical causes of CMs. Before the field survey, the study operationalised the theoretical CM variables within the research settings using a round one Delphi survey. Sourani and Sohail (2015) posited that a Delphi study is important for studies without prior quantitative evidence. Previous sections of this paper showed that pertinent knowledge about the cost of GB faces uncertainty. The Delphi study involved 12 professionals selected based on their expertise, experience, and research engagements in sustainable construction (Table 2). Studies have headlined educational and professional qualifications, experience, research engagement, and publication as the useful indicators of suitability for a Delphi study (Zahoor et al., 2017; Adjei et al., 2019). The experts profiled in Table 2 suit the study, and their review of theoretical CMs constructs in Table 1 appropriate. Influential variables from the Delphi survey were applied to develop the questionnaire. Studies adopting the Delphi approach are not certain about the appropriate number of rounds; however, the single round in this study is adequate to achieve the objective of the study (Sourani and Sohail, 2017; Zahoor et al., 2017).

Table 2: Profile of expert in Delphi study

\begin{tabular}{lllll}
\hline Industry roles of panelists & No & Experience & Certification & Education \\
\hline Certified Green experts & 4 & $20-30$ years & Green Star SA, LEEDS & MSc, MSc, BSc, MSc \\
Researchers in sustainable construction & 4 & $10-20$ years & Registered professional & PhDs \\
Experience in SB projects & 4 & $15-35$ years & Registered professional & MSc, MSc, BSc and BSc \\
\hline
\end{tabular}

\subsection{Survey}


The administration of the questionnaire adopted the face-to-face method to reach the targets based on professional networks. The population comprised a spectrum of construction professionals in South-South Nigeria. The population frame of 1018 was obtained through preliminary inquiries from professional bodies and the board of the emerging Green Building Council of Nigeria. The population comprised architects, builders, engineers, and quantity surveyors. The minimum sample size of the study, obtained using the Kish equation (Enshassi et al., 2012) was 208. However, the administration of the questionnaire doubled the minimum sample size to improve the response rate and to eliminate non-response bias (Kelfve et al., 2017). The research administered 415 questionnaires but retrieved 254 valid responses after three rounds. The study, therefore, recorded a response rate of $66 \%$, while the survey efficiency rate achieved was $61.21 \%$. These thresholds are significant in the face of the various challenges associated with surveys generally (Zhang et al., 2018). The valid response (254) is also greater than the minimum sample size (208) by $22 \%$. The quality of the research instrument showed the variables are valid measurement constructs for evaluating the causes of CM (Cronbach alpha $0.894>0.70$ ). Therefore, the significant response rate is consistent with participants' broad understanding of the research subject (Kelfve et al., 2017).

\subsection{Data analysis}

The data analysis sought to generate the principal causes of $\mathrm{CM}$ in which dimension reduction (factor analysis) was imperative. The research further validated the principal causes using Fussy Set Theory. Descriptive data analysis used mean item score (MIS) and Relative Important Index (RII) to determine the hierarchy of factors. Mean score is the average of a distribution, scores close to and above 3.00 are adopted benchmarks for determining a critical factor (Enshassi et al., 2012). The test of hypothesis involved Kruskal Wallis test. The acceptance or rejection of the hypothesis adopted the p-values $( \pm 0.05)$. RII was applied to generate ordinal indices for ordering the degree of influence of potential causes of CM based on experts' opinion in the Delphi survey. RII is the ratio of the sum of scores assigned by participants upon the product of sample size and the largest integer in the Likert scale (Holt, 2014). A rich literature exists on the principles and application of factor analysis (Field, 2005; Alashwal and Al-Shabahi, 2018) and Fussy Set Theory (FST) (Shen et al., 2012; Yudollahi et al., 2014). The survey data qualified for factor analysis since the measurement variables spread across global literature (see Table 1; Field, 2005). FST eliminates fussiness in ordinal data (Shen et al., 2012). The tool involves the computation of (1) the mean and standard deviation, (2) Z-score, (3) degree of association using Excel NORMDIST function, and (4) setting benchmark to determine the critical factor (Ekung et al., 2020). The degree of association of a variable to the set of critical causes of CM in FST analysis adopted the value of lambda cut benchmark $(\lambda>0.70)$ (Shen et al., 2012; Ekung et al., 2020).

\section{Results}

\subsection{Results of first round Delphi study}

Table 3 shows the most influential causes of CM based on selected experts' perceptions of their applicability to the research setting (Delphi survey). The results embed the theoretical causes of CM within the research's settings using two bands of RII, good $(0.70-0.890)$ and acceptable (0.60 to 0.69 ) (Holt, 2014). Twenty-six (74\%) factors are very strong causes of CM (RII > 0.70), while the degree of influence of nine $(26 \%)$ factors is merely acceptable. Low education and 
training, the scope of green features in the building, and poor accounting of benefits are the top three factors underpinning CMs. Table 3 reinforces the conceptual framework of the study by revealing that $\mathrm{CM}$ are derivatives of knowledge, cost management, and sustainability gaps. The tailored research conceptualization is consistent to explain the cause of CM in GB development. Overall, the 35 theoretical constructs are influential, significant, and prevalent causes of CM in the research setting.

Table 3: Degree of commonness on CM based on first round Delphi study

\begin{tabular}{lcc}
\hline Drivers of CM & RII & Remarks \\
\hline Reliance on cost data from oversea literature & .631 & Acceptable \\
Low knowledge of GB practices & .622 & Acceptable \\
Low prioritization of GB & .644 & Acceptable \\
Unwillingness to pay a rent for intangible benefits & .736 & Good \\
Inflation of the true cost to address immeasurable risks & .762 & Good \\
Dearth of empirical data & .764 & Good \\
Uncertainty of cost data & .713 & Good \\
Penchant to historical costs & .780 & Good \\
Low risk perceptions & .660 & Acceptable \\
Asymmetric information structure of the industry & .676 & Acceptable \\
Inability to let-off historical cost & .756 & Good \\
Cost estimate assumptions used & .726 & Good \\
Cost-benefits estimating techniques/methodological gaps & .771 & Good \\
Incongruity in costs data collection & .715 & Good \\
Cost data sample biases & .735 & Good \\
Poor discounting of costs & .629 & Acceptable \\
Poor costs accounting of benefits and processes & .807 & Good \\
Lack of awareness that cost are reducing due to improved knowledge & .742 & Good \\
Low education and training & .842 & Good \\
Skills shortage & .802 & Good \\
Secrecy and proprietary nature of costs information & .771 & Good \\
Reliance on costs of exemplar projects & .697 & \\
Lack and non-application of incentives to extra costs & .745 & Good \\
Attitudinal problems (prejudice that cost is high) & .752 & Good \\
Increased risk perception & .655 & Good \\
Misreading of economic financial benefits & .731 & Good \\
High capital costs & .828 & Good \\
Low market value & .674 & Acceptable \\
Adopting lifecycle costing to account for short-term benefit & .661 & Acceptable \\
Short-termism expectations against long-term value & .618 & Acceptable \\
Scope of sustainability features integrated drives extra costs & .828 & Good \\
Unfamiliarity with performance metric than costs & .794 & Good \\
Project characteristics (size, type and location) & .702 & Good \\
Sustainability level & .734 & Good \\
Project management factors & .755 & Good \\
\hline
\end{tabular}

\section{RII = Relative Important Index}

\subsection{Survey respondents' characteristics}

The study conducted a survey to validate the spread of the causes of CM and their degree of influence across the population of construction professionals. The spread of these factors across a larger sample is significant for generalizing their implications across settings. Table 4 presents the demographic analysis of participants' attributes in the study. The distribution of professional disciplines in the study is heterogeneous except for the quantity surveyors. This distribution pattern is, however appropriate for research in cost management since more quantity surveyors participated in the survey. All the respondents were registered professionals with an average experience between 10 to 15 years. The educational qualifications of respondents are also cogent 
with the first degree in the relevant fields, as well as postgraduate qualifications (47\%). The data related to participants' disciplines, experience, and knowledge of GB are appropriate to endorse the research findings.

Table 4: Respondents profile

\begin{tabular}{llllll}
\hline Professions & \multicolumn{5}{c}{ Professional registration } \\
\hline Architects & 44 & 17.00 & Registered & 254 & 100 \\
Builders & 34 & 13.00 & Others & 0 & 0.00 \\
Engineers & 30 & 12.00 & Total & 254 & 100.0 \\
Estate surveyors & 36 & 14.00 & Category & & \\
Quantity surveyors & 76 & 30.00 & Green building experts & 24 & 10.00 \\
Others & 34 & 13.00 & Construction professionals & 154 & 61.00 \\
Total & 254 & 100 & Property developer/clients & 76 & 30.00 \\
Educational qualifications & & & Years of experience & & \\
First degree/HND & 136 & 54.00 & $0-10$ & 122 & 48.00 \\
Master degree & 108 & 43.00 & $10-20$ & 76 & 30.00 \\
PhD & 10 & 4.00 & $20-30$ & 38 & 15.00 \\
Total & 254 & 100 & 30 and above & 18 & 7.00 \\
\hline
\end{tabular}

\subsection{Descriptive analysis of causes of CM}

Table 5 shows the hierarchy of $35 \mathrm{CM}$ factors based on the mean item score (MIS). The results are based on three practice areas in which the respondents were selected to show the rating pattern of each group. The MIS is in three categories, namely: scores $<2.50$ that cannot add up to 3.00, scores $>2.5<3.00$, and scores $>3.00$. The aggregated MIS reveals 20 factors $(57 \%)$ achieved ratings above 3.00, but overall, 27 (77\%) factors add-up to 3.00 and above to emerge important causes of CMs. Seven factors (23\%), however, obtained low ratings; the MIS for this group of factors is less than 2.50. The top five important causes of CM converged towards cost management-related gaps, namely: assumptions used in cost estimates, cost inflation to buffer immeasurable risks, the inclination to historical costs, uncertainty in cost data, and unreliable cost data. Based on these results, the study postulates that proper cost management would reduce $\mathrm{CM}$. The result agrees with extant postulation in the literature, that CMs are contingent derivatives of defective cost management (Pearce, 2008). The prior theory of this study introduced CM, as antecedents of overestimation and overvaluation of GB costs, the primacy of cost management factor is a valid inference of the study. However, factors supporting sustainability accounting and knowledge gaps emerged the least in the hierarchy of factors underpinning CM. The factors in this category include misunderstanding of economic benefits, high capital costs, low market value, as well as skills shortages. Between practices (groups), the results reveal the hierarchy of important causes of $\mathrm{CM}$ is similar across groups. The top five aggregated sources of CMs are also within the top five-rating factors in two or three practice areas to suggest consistent perception in CM factors. A comparison between the results in Tables 3 and Table 5 shows the numbers of important CM factors are related that is, 26 and 27 respectively. However, the apparent convergence in perceptions of respondents was further examined using the test of variance.

\subsection{Test of variance in respondents' perceptions of CM factors}

The test of variance determined the hypothesis of the study (Ho). The null hypothesis postulated that respondents' perceptions of principal causes of CM do not differ across the practice areas. The determination of this hypothesis involved Kruskal Wallis $\mathrm{H}$ test and its validity depended on 
the p-values. Table 6 shows that the inter-practice perceptions are consistent in the corroboration of the results in Table 5. The p-values for the three groups are less than 0.05 and the null hypothesis was rejected. The alternative position is acceptable and valid, that is, the knowledge and perceptions of principal causes of CM are consistent across practice areas.

Table 5: Descriptive analysis of causes of costs misperceptions in GB

\begin{tabular}{|c|c|c|c|c|c|c|c|c|c|}
\hline \multirow[t]{2}{*}{$\mathbf{S} / \mathbf{N}$} & \multirow[t]{2}{*}{ Drivers of misperceptions } & \multicolumn{2}{|c|}{$\begin{array}{c}\text { Green bldg. } \\
\text { experts }\end{array}$} & \multicolumn{2}{|c|}{$\begin{array}{l}\text { Construction } \\
\text { Professionals }\end{array}$} & \multicolumn{2}{|c|}{ Developers/Clients } & \multicolumn{2}{|c|}{ Group average } \\
\hline & & MS & Rank & MS & Rank & MS & Rank & MS & Rank \\
\hline 1 & $\begin{array}{l}\text { Reliance on cost data from } \\
\text { oversea literature }\end{array}$ & 3.03 & $22^{\text {nd }}$ & 2.97 & $21^{\mathrm{st}}$ & 3.03 & $19^{\text {th }}$ & 3.01 & $20^{\text {th }}$ \\
\hline 2 & Low knowledge of SB practices & 3.17 & $17^{\text {th }}$ & 3.20 & $18^{\text {th }}$ & 3.18 & $10^{\text {th }}$ & 3.18 & $18^{\text {th }}$ \\
\hline 3 & Low prioritization of SB & 3.19 & $16^{\text {th }}$ & 3.60 & $4^{\text {th }}$ & 3.27 & $7^{\text {th }}$ & 3.36 & $10^{\text {th }}$ \\
\hline 4 & $\begin{array}{l}\text { Unwillingness to pay a rent for } \\
\text { intangible benefits }\end{array}$ & 3.36 & $7^{\text {th }}$ & 3.71 & $3^{\text {rd }}$ & 3.42 & $5^{\text {th }}$ & 3.50 & $6^{\text {th }}$ \\
\hline 5 & $\begin{array}{l}\text { Inflation of the true cost to } \\
\text { address immeasurable risks }\end{array}$ & 3.56 & $5^{\text {th }}$ & 3.74 & $1^{\text {st }}$ & 3.64 & $3^{\text {rd }}$ & 3.64 & $2^{\text {nd }}$ \\
\hline 6 & Dearth of empirical data & 3.50 & $6^{\text {th }}$ & 3.51 & $9^{\text {th }}$ & 3.09 & $17^{\text {th }}$ & 3.38 & $8^{\text {th }}$ \\
\hline 7 & Uncertainty of cost data & 3.72 & $2^{\text {nd }}$ & 3.40 & $11^{\text {th }}$ & 3.52 & $4^{\text {th }}$ & 3.55 & $4^{\text {th }}$ \\
\hline 8 & Penchant to historical costs & 3.72 & $2^{\text {nd }}$ & 3.74 & $1^{\text {st }}$ & 3.12 & $15^{\text {th }}$ & 3.54 & $5^{\text {th }}$ \\
\hline 9 & Low risk perceptions & 3.36 & $7^{\text {th }}$ & 3.23 & $17^{\text {th }}$ & 3.03 & $19^{\text {th }}$ & 3.21 & $16^{\text {th }}$ \\
\hline 10 & $\begin{array}{l}\text { Asymmetric information structure } \\
\text { of the industry }\end{array}$ & 3.31 & $11^{\text {th }}$ & 3.14 & $20^{\text {th }}$ & 3.12 & $15^{\text {th }}$ & 3.19 & $17^{\text {th }}$ \\
\hline 11 & Inability to let-off historical cost & 3.58 & $4^{\text {th }}$ & 3.37 & $14^{\text {th }}$ & 3.73 & $1^{\text {st }}$ & 3.56 & $3^{\text {rd }}$ \\
\hline 12 & Cost estimate assumptions used & 3.78 & $1^{\text {st }}$ & 3.54 & $6^{\text {th }}$ & 3.73 & $1^{\mathrm{st}}$ & 3.68 & $1^{\mathrm{st}}$ \\
\hline 13 & $\begin{array}{l}\text { Cost-benefits estimating } \\
\text { techniques/methodological gaps }\end{array}$ & 3.31 & $11^{\text {th }}$ & 3.51 & $9^{\text {th }}$ & 3.42 & $5^{\text {th }}$ & 3.41 & $7^{\text {th }}$ \\
\hline 14 & $\begin{array}{l}\text { Incongruity in costs data } \\
\text { collection }\end{array}$ & 3.17 & $17^{\text {th }}$ & 3.54 & $6^{\text {th }}$ & 3.27 & $7^{\text {th }}$ & 3.33 & $11^{\text {th }}$ \\
\hline 15 & Cost data sample biases & 3.08 & $19^{\text {th }}$ & 3.37 & $14^{\text {th }}$ & 3.06 & $18^{\text {th }}$ & 3.17 & $19^{\text {th }}$ \\
\hline 16 & Poor discounting of costs & 3.36 & $7^{\text {th }}$ & 3.40 & $11^{\text {th }}$ & 3.18 & $10^{\text {th }}$ & 3.32 & $13^{\text {th }}$ \\
\hline 17 & $\begin{array}{l}\text { Poor costs accounting of benefits } \\
\text { and processes }\end{array}$ & 2.89 & $26^{\text {th }}$ & 2.89 & $23^{\text {rd }}$ & 3.15 & $14^{\text {th }}$ & 2.97 & $22^{\text {nd }}$ \\
\hline 18 & $\begin{array}{l}\text { Lack of awareness that cost are } \\
\text { reducing due to improved } \\
\text { knowledge }\end{array}$ & 3.36 & $7^{\text {th }}$ & 3.54 & $6^{\text {th }}$ & 3.18 & $10^{\text {th }}$ & 3.37 & $9^{\text {th }}$ \\
\hline 19 & Low education and training & 3.31 & $11^{\text {th }}$ & 3.60 & $4^{\text {th }}$ & 3.03 & $19^{\text {th }}$ & 3.32 & $13^{\text {th }}$ \\
\hline 20 & Skills shortage & 2.39 & $30^{\text {th }}$ & 2.43 & $29^{\text {th }}$ & 2.12 & $31^{\text {st }}$ & 2.32 & $31^{\text {st }}$ \\
\hline 21 & $\begin{array}{l}\text { Asymmetry, secrecy and } \\
\text { proprietary nature of costs } \\
\text { information in the construction } \\
\text { industry }\end{array}$ & 2.94 & $23^{\mathrm{rd}}$ & 3.17 & $19^{\text {th }}$ & 2.88 & $22^{\text {nd }}$ & 3.00 & $21^{\mathrm{st}}$ \\
\hline 22 & $\begin{array}{l}\text { Reliance on costs of exemplar } \\
\text { projects }\end{array}$ & 2.72 & $27^{\text {th }}$ & 2.83 & $24^{\text {th }}$ & 2.85 & $23^{\text {rd }}$ & 2.80 & $24^{\text {th }}$ \\
\hline 23 & $\begin{array}{l}\text { Lack and non-application of } \\
\text { incentives to extra costs }\end{array}$ & 3.08 & $19^{\text {th }}$ & 2.94 & $22^{\text {nd }}$ & 2.55 & $24^{\text {th }}$ & 2.87 & $23^{\text {rd }}$ \\
\hline 24 & $\begin{array}{l}\text { Attitudinal problems (prejudice } \\
\text { that cost is high) }\end{array}$ & 2.53 & $29^{\text {th }}$ & 2.40 & $30^{\text {th }}$ & 2.18 & $29^{\text {th }}$ & 2.38 & $29^{\text {th }}$ \\
\hline 25 & Increased risk perception & 2.28 & $32^{\text {nd }}$ & 2.49 & $26^{\text {th }}$ & 2.36 & $27^{\text {th }}$ & 2.38 & $29^{\text {th }}$ \\
\hline 26 & $\begin{array}{l}\text { Misreading of economic financial } \\
\text { benefits }\end{array}$ & 1.94 & $34^{\text {th }}$ & 1.80 & $35^{\text {th }}$ & 1.79 & $33^{\text {rd }}$ & 1.85 & $34^{\text {th }}$ \\
\hline 27 & High capital costs & 2.25 & $33^{\text {rd }}$ & 1.89 & $33^{\text {rd }}$ & 1.70 & $34^{\text {th }}$ & 1.95 & $33^{\text {rd }}$ \\
\hline 28 & Low market value & 2.33 & $31^{\mathrm{st}}$ & 2.34 & $32^{\text {nd }}$ & 2.18 & $29^{\text {th }}$ & 2.29 & $32^{\text {nd }}$ \\
\hline 29 & $\begin{array}{l}\text { Adopting lifecycle costing to } \\
\text { account for short-term benefit }\end{array}$ & 1.86 & $35^{\text {th }}$ & 1.83 & $34^{\text {th }}$ & 1.82 & $32^{\text {nd }}$ & 1.84 & $35^{\text {th }}$ \\
\hline 30 & $\begin{array}{l}\text { Short-termism expectations } \\
\text { against long-term value }\end{array}$ & 2.92 & $24^{\text {th }}$ & 2.46 & $27^{\text {th }}$ & 2.85 & $23^{\text {rd }}$ & 2.74 & $25^{\text {th }}$ \\
\hline 31 & Sustainability features in included & 2.56 & $28^{\text {th }}$ & 2.46 & $28^{\text {th }}$ & 2.55 & $24^{\text {th }}$ & 2.52 & $28^{\text {th }}$ \\
\hline 32 & $\begin{array}{l}\text { Unfamiliarity with performance } \\
\text { metric than costs }\end{array}$ & 3.31 & $11^{\text {th }}$ & 3.34 & $16^{\text {th }}$ & 3.18 & $10^{\text {th }}$ & 3.28 & $15^{\text {th }}$ \\
\hline 33 & Project characteristics (size, type & 3.36 & $7^{\text {th }}$ & 3.40 & $11^{\text {th }}$ & 3.21 & $9^{\text {th }}$ & 3.33 & $11^{\text {th }}$ \\
\hline
\end{tabular}




\begin{tabular}{llllllllll}
\hline & and location) & & & & & & & & \\
& & & & & & \\
34 & Certification level & 3.06 & $21^{\text {st }}$ & 2.66 & $25^{\text {th }}$ & 2.45 & $26^{\text {th }}$ & 2.73 & $26^{\text {th }}$ \\
35 & Project management factors & 2.83 & $25^{\text {th }}$ & 2.40 & $30^{\text {th }}$ & 2.36 & $27^{\text {th }}$ & 2.54 & $27^{\text {th }}$ \\
\hline
\end{tabular}

Table 6: Tests of variation in respondents perceptions of costs misperception factors

\begin{tabular}{lcccc}
\hline Respondents & Chi-Square & Df & Asymp. Sig. & Decision \\
\hline Green building experts & 18.054 & 2 & .000 & Reject $\mathrm{H}_{\mathrm{o}}$ \\
Construction professionals & 15.618 & 2 & .000 & Reject $\mathrm{H}_{\mathrm{o}}$ \\
Developers/client & 13.796 & 2 & .001 & Reject $\mathrm{H}_{\mathrm{o}}$ \\
\hline
\end{tabular}

a. Kruskal Wallis Test

b. Grouping Variable: category of respondents

\subsection{Principal causes of $C M$}

The reliability of the principal factor analysis and the pattern of the relationship was adequate (determinant of the correlation matrix, $0.0003109>0.0001$; KMO, $0.621>0.50$; Field, 2005). The explained variance was $72.16 \%$ from 12 components. Table 7 shows the rotated component matrix of the principal $\mathrm{CM}$ factors (bold prints) for compressed loadings 0.5 and above. The principal causes of CMs are high capital costs, cost data sample size bias, low knowledge of GB practices, short-termism expectations against long-term value, cost inflation to address immeasurable risks, and lack of awareness that cost is reducing through improved knowledge and implementation practices. Others are non-familiarity with performance metrics than costs, wrong cost estimating assumptions, uncertainty in cost data, and reliance on costs of exemplar projects, skills shortages, and poor defective sustainability cost accounting.

Table 7: Rotated Component Matrix ${ }^{a}$ of causes of costs misperceptions in GB

\begin{tabular}{|c|c|c|c|c|c|c|c|c|c|c|c|c|}
\hline \multirow[t]{2}{*}{ Principal components } & \multicolumn{12}{|c|}{ Components } \\
\hline & $\mathbf{1}$ & $\mathbf{2}$ & 3 & 4 & 5 & 6 & 7 & $\mathbf{8}$ & 9 & $\mathbf{1 0}$ & 11 & 12 \\
\hline $\begin{array}{l}\text { Low knowledge of SB practices } \\
\text { Low prioritization of SB }\end{array}$ & & & .742 & & & & & & & & & \\
\hline $\begin{array}{l}\text { Unwillingness to pay a rent for intangible } \\
\text { benefits }\end{array}$ & & & & & .731 & & & & & & & \\
\hline $\begin{array}{l}\text { Inflation of the true cost to address } \\
\text { immeasurable risks }\end{array}$ & & & & & .757 & & & & & & & \\
\hline Dearth of empirical data & & & & & & & & & .675 & & & \\
\hline Uncertainty of cost data & & & & & & & & & .714 & & & \\
\hline Inability to let-off historical cost & & & & & & & & .732 & & & & \\
\hline Cost estimate assumptions used & & & & & & & & .765 & & & & \\
\hline Cost data sample biases & & .751 & & & & & & & & & & \\
\hline Poor discounting of costs & & .682 & & & & & & & & & & \\
\hline $\begin{array}{l}\text { Poor costs accounting of benefits and } \\
\text { processes }\end{array}$ & & & & & & & & & & & .659 & \\
\hline $\begin{array}{l}\text { Lack of awareness that cost are reducing due } \\
\text { to improved knowledge }\end{array}$ & & & & & & .818 & & & & & & \\
\hline Low education and training & & & & & & .802 & & & & & & \\
\hline Skills shortage & & & & & & & & & & & & .863 \\
\hline Reliance on costs of exemplar projects & & & & & & & & & & .817 & & \\
\hline $\begin{array}{l}\text { Lack and non-application of incentives to extra } \\
\text { costs }\end{array}$ & & & & & & & & & & & & \\
\hline Misreading of economic financial benefits & .810 & & & & & & & & & & & \\
\hline High capital costs & .827 & & & & & & & & & & & \\
\hline $\begin{array}{l}\text { Focus on short-term gains against long-term } \\
\text { value for money }\end{array}$ & & & & .715 & & & & & & & & \\
\hline Sustainability features in included & & & & .692 & & & & & & & & \\
\hline
\end{tabular}


Unlike the prevalence of cost management factors only in Section 4.3, the results of principal component analysis shows that the three postulated causes of CM (Figure 1-conceptual framework) are significant and consistent with the result of the Delphi study. The components related to SAG include defective sustainability accounting and non-familiarity with performance metrics than costs. Cost management gaps-related drivers are wrong cost-estimating assumptions, uncertainty in cost data, cost data sample size bias, and cost inflation to address immeasurable risks. Reliance on the cost of exemplar projects, skills shortages, low knowledge of SB practices, short-termism expectations against long-term value, high capital costs, and lack of awareness that cost is reducing are knowledge gap-related factors.

\subsection{The validity of principal CM factors}

The validity of the principal causes of CM involved FST. The test evaluated the association of the 12 principal components in Table 7 to the set of causes of CMs based on the value of Lambda cut $(\lambda,>0.70)$. Table 8 shows seven out of twelve components are significant $(\lambda$-cut, $0.702-0.771>$ 0.70 ). The significant CM factors are knowledge of GB practices, inflation of true costs to address incalculable risks, sample bias in cost data, and poor sustainability costs accounting among others. The fundamentals of these components are adequate to explain the existence of CM in GB. Four other components $(\lambda$-cut $<0.70)$ despite emerging the principal components of CM (Table 7 ) are non-critical causes that can explain CM. The implications suggest that skills shortages, estimating assumptions, misunderstanding the capital costs, sustainability features incorporated in buildings, and short-termism in benefits against long-term focus are established fundamental problems for the cost of GB. The severity of these factors cannot influence the cost perceptions of stakeholders in GB adoption.

\begin{tabular}{llccc} 
Table 8: Significance of critical drivers of costs misperceptions in GB \\
\hline Categories & Components of costs misperceptions drivers & $\begin{array}{c}\text { Z- } \\
\text { score }\end{array}$ & \multicolumn{2}{l}{ Domains } \\
\hline Knowledge gap & Low knowledge of SB practices & .638 & .738 & Significant \\
& Lack of awareness that cost are reducing due to & .698 & .757 & Significant \\
& improved knowledge & & & \\
& Cost data sample biases & .743 & .771 & Significant \\
Cost management gap & Inflation of the true cost to address immeasurable risks & .530 & .702 & Significant \\
& Reliance on costs of exemplar projects & .538 & .705 & Significant \\
Sustainability accounting & Poor costs accounting of benefits and processes & .550 & .709 & Significant \\
& Unfamiliarity with performance metric than costs & .548 & .708 & Significant \\
& & & & \\
& Skills shortage & -.956 & .170 & Significant \\
& Cost estimate assumption used & .202 & .580 & Not sig. \\
& High capital costs & -1.720 & .043 & Not sig. \\
& Focus on short-term gains against long-term value for & -.190 & .424 & Not sig. \\
& money & & & \\
& Sustainability features included in the project & -.411 & .341 & Not sig. \\
\hline
\end{tabular}

Sig. = significant misperceptions, $\lambda=$ lambda cut (degree of association to a universal set of cost misperceptions drivers); Z-score is one of the four steps to determining critical association using FST (see Section 3.3).

\section{Discussions}

5.1 Sustainability accounting gap (SAG) factors 
Ineffective accounting systems and non-familiarity with performance metrics are SAG-related factors underlying CM. Enormous evidence abound that buttress the severity of these drivers such as the dearth of suitable tools and standards in accounting for the comprehensive dimensions of sustainability and non-familiarity with sustainability cost performance assessment criteria. The search to reduce CM, therefore, requires appropriate standards and increased awareness in sustainability performance assessment. In addition, proper value and frames would also benefit the 'bigger-than-self' sustainability assessment issue (Arvai et al., 2012). Current understanding tends to undervalue the pay-off functions and set cost as the deciding factor. Proper awareness and education about the values of derivable pay-offs would improve decision-making. Achieving this objective demands a balanced budgeting approach that can account for the discrete processes and pay-off functions in GB. Even though lifecycle assessment approaches (LCA) are available for comprehensive sustainability assessment, low awareness, skills gaps, and the dearth of data inhibit their uses (Dwaikat and Ali, 2016). SAG further exposed the distortions in existing sustainability accounting approaches; hence, the decision to integrate sustainability concerns into project development relies on incorrect information. The problem of asymmetric information is pronounced among clients who are unable to demand sustainability integration in project development (Adabre et al., 2020). SAG also increases uncertainty, even though the development of GB is laden with many unknowns (Halliday, 2008). Lack of details about the sustainability of assessed buildings for instance, has raised uncertainty concerning their factual cost implications (Emmanuel, 2011). Information certainty would benefit cost accounting since the cost has definite parameters. Lack of details about assessed buildings, therefore, constitutes a disincentive contributing to misperceptions. Uncertain information and the dearth of requisite details further widen the gap between high-costs and the implication of good practices in projects and trigger doubts about the ability of blue-chip projects to achieve similar rating performance in another tool (Emmanuel, 2011). This controversy validates the consistency of the second principal component of SAG in Table 8 that is, non-familiarity with performance metrics. As the awareness of

performance metrics increases, the consensus in sustainability cost accounting would facilitate certainty of cost information.

\subsection{Knowledge gap factors}

Knowledge gap (KNG) related principal causes of CMs are low knowledge of GB practices, cost data sample size bias, and lack of awareness that cost is reducing. Until these pertinent issues are resolved, the supposition of whether the cost of GB is high would remain polemic. Even though a section of the literature attributed the high-cost of GB to green features, sustainability concern is a negligible aspect of the total building systems (Emmanuel, 2011). Moreover, since ordinary certification is possible at a lower extra cost than feared (Ekung, 2019; Sun et al., 2019), CMs correlates with the misunderstanding of cost factors. The substance of extra cost is soft costsdependent (Abidin and Azizi, 2016), hence, linking high-cost to hard cost is both overvalued and overestimated beliefs (Kovach et al., 2015). Statistical evidence also showed that the cost of GB does not differ significantly from the alternate construction approach (Syphers et al., 2003; Langdon, 2007). The incorporation of high-end, high sustainability credit technologies such as photovoltaic panels and geothermal heat pumps have less influence on capital costs (Gilmour et al., 2013). CMs are not just associated with information/knowledge gaps but poses high-risk perception problems (Zhou and Lowe, 2003). Overall, embedding suitable knowledge of GB cost 
information, practices development; requisite experience, supply chain supports, and improved performance measurement would reduce CMs.

\subsection{Cost management gap factors}

The principal cost management factors underpinning CMs comprised a spectrum of issues troubling effective cost forecasting and control. The study validated the inflation of the true cost to address risks and reliance on the cost of exemplar projects as the principal CMG-related factors driving CM. Faulty conventions during cost estimation have two implications on the lifecycle cost of GB. First, a high initial cost of construction would produce low maintenance/operating costs and second, low initial cost decisions have high operating costs (Pearce, 2008). The risk perceptions in GB are low (Górecki and Díaz-Madroñero, 2020), therefore, cost inflation is a strategy in budgeting for perceived high risks. Moreover, cost estimates have definite inclusions and exclusions, but cost inflation lacks a scientific guide to justify their inclusions in GB estimates. In addition, the cost of GB in the literature develops from exemplar projects, and the practices underlying exemplar projects in specifications and design are global best practices. Developing ground rules for understanding estimates of GB based on related projects must separate the cost of essential requirements from the cost of 'nice to have' (Syphers et al., 2003; Pearce, 2008). The cost of projects also embraces non-project-specific expenditures that are difficult to estimate in accurate terms such as soft costs. Until comprehensive cost management protocols develop, the cost of GB would remain one-sided, accounting mainly for inputs only. Aspects of budgeting for the discrete processes of the GB would likewise remain prosaic owing to the dearth of comprehensive cost management protocols (Choi, 2009).

\subsection{Practical and theoretical implications}

The study shows that CMs do not only obstruct rational decision processes but also have developed into a belief system. An inclination to the unsupported beliefs decimates the pay-off incentives for reinforcing GB adoption decisions due to their deceptive consequences. Since CMs rely on information in the unrestricted space, clients and developers must reduce the dependence on published cost information, and consult with skilled professionals and a certified information database for effective CM management. However, the study notes the uses of GB information by the experienced and inexperienced stakeholders do not differ (Carter, 2007; WGBC, 2016; SBMS, 2019). Rational decisions are exclusive to experts who can assess scientific information (Paek and Hove, 2017); based on this understanding, professionals' valid knowledge of cost is inclusive to growing GB adoption. The knowledge of CM drivers would bridge the dichotomy in the use of GB information through the guides developed from the state of the environment. In view of this contribution, the causes of CMs suit any prevalent non-factual shortcuts in an environment adapted to form opinion about the cost of GB. The causes of CMs therefore constitute a naturally interpreted parameter for effective decision-making and misperception management.

Information about the causes of CMs are appropriate for managing misperception as well as GB adoption. The study reveals CMs are not abstract as portrayed in the literature but develop from factors understood by the stakeholders in the environment. CMs and their relationship with the choice of GB were analysed to show the strategic role of developing regional practices in reducing CMs. Improving regional practices would enhance the quality of evidence imperative to advancing the factual knowledge of cost in GB development. Short and medium-term strategies for the developing countries could target the development of standards, performance measurement 
metrics, and awareness, education, and training. Universally, the position of this paper has resuscitated the abandoned discourse on methodological gaps in GB costs and benefits quantifications. Educators and other stakeholders in the construction industry need to become aware of the causes of $\mathrm{CM}$ to inculcate appropriate perceptions imperative to GB adoption. The study will correct negative perceptions retained by stakeholders that obstruct the willingness to adopt GB. However, correcting misperceptions must apply cautions based on indications that such actions may not achieve a change (Flynn et al., 2017).

\section{Conclusion}

The search for the relevant strategies to improve the adoption of Green Buildings (GB) situates the factual knowledge of their financial implications at the heart of rational decision-making. The expanding volume of the literature reveals the cost of GB is misread more prohibitive than alternate construction approaches. Stakeholders parade these misperceptions into the decision processes and the consequence is the disparaging low adoption of GB across the globe. The literature charitably acknowledged these unsupported beliefs as the pertinent adoption barrier without factual expositions of their causes. This study provides answers to the reason why construction stakeholders retain unsupported beliefs about the cost of GB. Causes of CM dragging the adoption of GBs have varying dimensions. The taxonomy of important causes outlined knowledge, cost management, and sustainability accounting gaps. This position suggests that current knowledge, cost management, and sustainability accounting practices are inadequate, and improving these dimensions would direct appropriate cost perception in GB development. Overall, the causes of CMs converge towards seven principal factors including low knowledge of GB practices, non-familiarity with performance metrics, inadequate evidence, poor-risk perceptions, and reliance on the costs of exemplar projects. Their possible deceptive consequences tend to disrupt adoption decisions by disconnecting adopters from the pay-off incentives in GB development. Low adoption of GB across the globe reinforces the practice implications of the validated unsupported beliefs beyond the decision interface.

The study buttresses the need to improve CMs to deliver appropriate cost perception imperative to grow GB adoption. The anticipated improvement must disseminate innovations in GB practices; advance awareness, education, training, cost management, sustainability accounting, and risk perceptions as antecedents of the significant CM factors. Despite the regional inclination of the data underpinning the result of this study, developed and developing countries' settings must improve knowledge, and enhance cost management and sustainability accounting efficiency to overcome CM-related barriers. These results may concede to possible variations along with regional contexts due to differing maturity levels in GB development. Investigating this problem using data from the developed markets would reinforce their universal assumptions and broaden the understanding of CM factors. 


\section{References}

Abidin, N.Z. and Azizi, N.Z. (2016), "Identification of factors influencing costs of green projects', International Journal of Civil, Environmental, Structural, Construction and Architectural Engineering, Vol 10 No 9, pp.16-112. 10.5281/zenodo.1126421

Adabre, M.A., Chan, A.P.C., Dark, A., Osei-Kyei, R., Abidoye, R. and Adjei-Kumi, T. (2020), "Critical barriers to sustainability attainment in affordable housing: International construction professionals' perspective', Journal of Cleaner Production, 10.1016/j.jclepro.2020.119995.

Ade, R., (2018), 'The cost of Homestar: a case study on how to achieve a 6-10 Homestar rating for standalone and terraced housing in Hobsonville Point', https://www.branz.co.nz/cms_show_download.php?id=d2af546dc4c801cdefe3aacf23ab 2864252b00ea (Retrieved 5 December 2020).

Adjei, K.O. Aigbavboa, C.O and Thwala, W.D. (2019), 'Contractors organisational structure elements for controlling project costs in the construction industry', Springer Nature, 10.1007/978-3-319-94709-9_42.

Ahn, Y. H., Pearce, A. R., Wang, Y., and G., Wu. (2013), ''Drivers and barriers of sustainable design and construction: the perception of green building experience', International Journal of Sustainable Building Technology and Urban Development, Vol 4 No 1, pp.3545. 10.1080/2093761X.2012.759887

Alashwal, A.M. and Al-Shabahi, M.H. (2018), 'Risk factors in construction projects during unrest period in Yemen.' Journal of Construction in Developing Countries, Vol 23 No 2, pp.43- 62. 10.21315/jcdc2018.23.2.4

ARDOR (2020), 'Remove the perception that high costs when building green buildings.' http://www.ardorarch.com/news/detail-news/xoa-bo-quan-niem-cho-rang-chi-phi-caoRetrieved 29 March 2020.

Arvai, J., Campbell-Arvai, V. and Steel, P. (2012), 'Decision-making for sustainability: $a$ systematic review, 'London, Ontario: Network for Business Sustainability.

Barlett, E. and Howard, H. (2000). "'Informing the decision makers on the cost and value of green building." Building Research and Information, Vol 28 No 516, pp.315 -324. $\underline{10.1080 / 096132100418474}$

Bevan, W. and Lu, S.L. (2013), 'Green marketing in housing: reality or rhetoric?' In: Smith,

S.D. and Ahiaga-Dagbui, D.D. (Eds) Proceedings of $29^{\text {th }}$ Annual ARCOM Conference, 2-4 September 2013, Reading, UK, Association of Researchers in Construction Management, 1243-1252.

Bilec, M., Ries, R. and Mathews H. S. (2007), 'Sustainable development and green design-Who is leading the green initiative?' Journal of Professional Issues in Engineering Education and Practice, Vol 133 2007, pp.265-269. 10.1061/(ASCE)1052-3928(2007)133:4(265)

Bond, S. and Perrett, G. (2012), 'The key drivers and barriers to sustainable development of commercial property in New Zealand,' Journal of Sustainable Real Estate, Vol 4 No 1, pp.48-77. 10.1080/10835547.2012.12091834 
Buys, F. and Hurbissoon, R. (2011), 'Green buildings: a Mauritian built environment stakeholders' perspective', Acta Strutilia, Vol 18 No 1, pp.81-101.

Cartlidge, D. 2018. New Aspects of Quantity Surveying, London, Spon Press. ISBN978-1-13867376-2

Carter, E. (2007), ' 'Making money from sustainable homes: a developer's guide.' Published by CIOB, UK. PDM Consultants.

Chau, C.K., Leung, T.M., Lutzkendorf, T.P. and Balouktsi, M. (2013), 'A A review on barriers, policies and governance for green buildings', Sustainable Building 2013 Hong Kong Regional Conference Urban Density and Sustainability 12 -13 September 2013, 1-8.

Chegut, A., Eichholtz, P. and Kok, N. (2019), "The price of innovation: an analysis of the marginal cost of green buildings", Journal of Environmental Economics and

Management, Vol 98, 2019, pp.1-18. 10.1016/j.jeem.2019.07.003

Choi, C. (2009), 'Removing market barriers to green development: principles and action projects to promote widespread adoption of green development practices', Journal of Sustainable Real Estate, Vol 1 No 1, pp.107-138. 10.1080/10835547.2009.12091785

Darko, A., Chan, A.P.C., Ameyaw, E.E., He, B.J. and Olanipekun, A.O. (2017), 'Examining issues influencing green building technologies adoption: The United States green

building experts' perspectives', Energy and Buildings, 2017, 10.1016/j.enbuild.2017.03.060.

Dobson, D.W., Sourani, A., Sertyesilisik, B. and Tunstall, A. (2013), 'S Sustainable construction: analysis of its cost and benefits', American Journal of Civil Engineering and Architecture, Vol 1 No 2, pp.32-38. 10.21276/ijirem.2016.3.6.12

Dwaikat, L.N. and Ali, K.N. (2016), 'Green buildings cost premium: a review of empirical evidence.' Energy and Buildings, Vol 110, pp.396-403. 10.1016/j.enbuild.2015.11.021

Ekung, S., Adu, E. and Lashinde, A. (2020), 'System pathogens inhibiting construction project risk management performance: deliberate ignorance perspective', Journal of Building Performance, 11(1): 68-76. http://spaj.ukm.my/jsb/index.php/jbp/article/view/426 (accessed 22 October 2020)

Ekung, S. (2019), ' 'Development of sustainability costs models and optimisation strategies for buildings in South-South, Nigeria', PhD Thesis, University of Uyo, Nigeria.

Emmanuel, R. (2011), 'Sustainability, assessment and quantity surveying practice.' In: Cartlidge, $\quad$ D. (Ed) (2011). New Aspects of Quantity Surveying, London: Spon Press.

Enshassi, A., Arain, F. and Tayeh, B. (2012), 'Major causes of problems between contractors and subcontractors in the Gaza Strip', Journal of Financial Management of Property and Construction, Vol 17 No 1, pp.92-112. 10.1108/13664381211211064

Field, A. P. (2005), 'Discovering Statistics Using SPSS' Second Edition, London, Sage

Fischer, E.A. (2010), 'Issues in green building and the response: an introduction'. US Congressional Research Service.

Flynn, D.J., Nyhan, B., and Reifer, J. (2017), "The nature and origins of misperceptions: understanding false and unsupported beliefs about politics', Advances in Political Psychology, 38(S1), 127-150 10.1111/pops.12394.

Fuerst, F., Oikarinen, E. and Harjunen, O. (2016), 'Green signaling effects in the market for energy-efficient residential buildings,' Applied Energy, Vol 180, pp.560-571. 10.1016/j.apenergy.2016.07.076

Fullbrook, D., Jackson, Q. and Finlay, G. (2006), 'Value case for sustainable building in New Zealand', Ministry of Environment, New Zealand. 
Galuppo, L. A. and Tu, C. (2010), 'Capital markets and sustainable real estate: what are the perceived risks and barriers?', The Journal of Sustainable Real Estate, Vol 2 No 1, 143159. $10.1080 / 10835547.2010 .12091800$

Gilmour, D., Blackwood, D., Falconer, R, Isaacs, J. and Taylor. A. (2013), '’A knowledge map of sustainability for urban redevelopment projects", In: Smith, S D (Ed.) and AhiagaDagbui, D. D. (Eds.), Proceedings 29th Annual ARCOM Conference, 2-4 September 2013, Reading, UK, Association of Researchers in Construction Management, 579- 588.

Gluch, P., Gustafsson, M., Thuvander, L. and Baumann, H. (2013), 'Charting corporate greening: environmental management trends in Sweden', Building Research and Information, Vol 42 No 3, pp.318-329. 10.1080/09613218.2014.855873

Gossner, O. and Steiner, J. (2018), 'On the cost of misperception: General results and behavioural applications", Journal of Economic Theory, Vol 177, 2018, pp.816-847. 10.1016/j.jet.2018.08.003

Górecki, J. and Díaz-Madroñero, M. (2020), 'Who risks and wins - simulated cost variance in sustainable construction projects', Sustainability, Vol 12 No 3370, pp.1-31. $10.3390 / \mathrm{su} 12083370$

Halliday, S. 2008. Sustainable Construction, Oxford: Butterworth-Heinemann.

Häkkinen, T. and Belloni, K. (2011), 'Barriers and drivers for sustainable building', Building Research and Information, Vol 39 No 3, pp.239-255. 10.1080/09613218.2011.561948

Heerwagen, J. (2000), 'Green building, organizational success and occupant productivity'. Building Research \& Information, Vol 28 No 5/6, pp.353 367.

$\underline{10.1080 / 096132100418500}$

Hopkins, E. A. (2016). 'Barriers to adoption of campus green building policies. Smart and Sustainable Built Environment', Vol 5 No 4, pp.340-351. 10.1108/sasbe-07-2016-0016.

Hoffman, A. J. and Henn, R. (2008), ' 'Overcoming the social and psychological barriers to green building", Organization and Environment, Vol 21 No 4, pp.390-419. 10.2139/ssrn.1135236.

Hastie, R. and Dawes, R.M. (2009), 'Rational Choice in an Uncertain World-The Psychology of Judgment and Decision Making', 2nd edition, US, SAGE Publications.

Horhota, M., Asman, J., Stratton, J.P. and Halfacre, A.C. (2014), 'Identifying behavioral barriers to campus sustainability: a multi-method approach", International Journal of Sustainability in Higher Education, Vol 15 No 3, pp.343-358. 10.1108/IJSHE-07$2012-0065$.

Holt, G.D. (2014), 'Guest Editorial- Asking questions, analysing answers: relative importance', Construction Innovation, Vol 14 No 1, pp.1-11. 10.1108/CI-06-2012-0035.

Hosseini, M. R., Chileshe, N., Jepson, J., and Arashpour, M. (2016), 'Critical success factors for implementing risk management systems in developing countries", Construction Economics and Building, Vol 16 No 1, pp.18-32. 10.5130/AJCEB.v16i1.4651.

Hwang, B.G., Zhu, L., and Tan, J. S. H. (2017), 'Green business park project Management: Barriers and solutions for sustainable development', Journal of Cleaner Production, Vol 153, pp.209-219. 10.1016/j.jclepro.2017.03.210.

Hydes, K. and Creech, L. (2000), 'Reducing mechanical equipment cost: the economics of green design', Building Research and Information, Vol 28, No 5/6, pp.403 - 407. 10.1080/096132100418555.

Jerry, Y. (2005), "Marketing Green Buildings", Dollars and Sense of LEED and Green Buildings', HPAC Engineering Web Seminar, March 16, 2005, Publisher, Tanker Terry, HPAC. 
Kats, G. (2014), 'Israeli green buildings: costs and benefits', Greening Our Built World.

Kats, G.H. (2003), "The costs and financial benefits of green buildings', A Report to California's Sustainable Building Task Force Sacramento, CA.

Kats, G. (2010), Greening our Built World: Costs, Benefits, and Strategies. Island Press, Washington, D.C.

Kelfve, S., Thorslund, M. and Lennartsson, C. (2017), 'Sampling and non-response bias on health- outcomes in surveys of oldest old', European Journal of Ageing, Vol 10, pp.237245. 10.1007/s10433-013-0275-7.

Kokkonen, A. and Alin, P. (2015), 'Practice-based learning in construction projects: A literature review', Construction Management and Economics, Vol 33 No 7, pp.513-530. 10.1080/01446193.2015.1062903.

Kovach, N.S., Gibson, AS and Lamont, G.B. (2015), 'Hypergame theory: a model for conflict, misperception, and deception", Game Theory, 10.1155/2015/570639.

Kulczak, R, Piroozfar, P.A.E and Harder, M.K. (2015), 'Managing sustainability through decision processes: the influence of values and frames', In: Raidén, A.B and AboagyeNimo, E. (Eds) Proceedings 31 ${ }^{\text {st }}$ Annual ARCOM Conference, 7-9 September 2015, Lincoln, UK, Association of Researchers in Construction Management, 437-446.

Lavasani, H. (2018), 'Impact of green building certifications on the economic performance of real estate office assets: Net operating income, and market value", PhD Thesis, University of Maryland, USA.

Mapp, C., Nobe, M.C. and Dunbar, B. (2011), "The cost of LEED - an analysis of the construction costs of LEED and non-LEED banks", The Journal of Sustainable Real Estate, Vol 3 No 1, pp.254-273. 10.1080/10835547.2011.12091824.

Nduka, D.O., Ede, A.N., Oyeyemi, K.D. and Olofinnade, O.M. (2019), 'Awareness, benefits and drawbacks of net zero energy building practices: construction industry professionals' perceptions', Materials Science and Engineering, Vol 640 2019, 012026doi:10.1088/1757-899X/640/1/012026.

Ogunba, O. A. (2018), 'The relative costs and benefits of conventional and green buildings in Nigeria', The 18th AfRES Conference, Integrating the African Real Estate Market - An Agenda. AfRES. Abeokuta, Ogun State, Nigeria: African Real Estate Society, 2018.

Pearce, A. R. (2008), 'Sustainable capital Projects: leapfrogging the first cost barrier', Civil Engineering and Environmental Systems, Vol 25 No 4, pp.291-300. $10.1080 / 10286600802002973$

Peterson, M. (2009), 'An Introduction to Decision Theory: Cambridge Introductions to Philosophy', Cambridge University Press, Cambridge, UK.

Paek, H. and Hove, T. (2017), 'Risk perceptions and risk characteristics.' Oxford Research Encyclopedia, Communication. 10.1093/acrefore/9780190228613.013.283

Renner, B., Gamp, M., Schmalzle, R. and Schupp, H.T. (2015), 'Health risk perceptions', International Encyclopedia of the Social and Behavioural Sciences, Vol 2 No 10, pp.702709. 10.1016/i.copsyc.2015.03.012.

Reichardt, A. (2014), 'Operating expenses and the rent premium of energy star and LEED certified buildings in the central and eastern US', The Journal of Real Estate Finance

and Economics, Vol 49 No 3, pp.413-433. 10.1007/s11146-013-9442-z.

Rott, H. (2011), 'Odd choices: on the rationality of some alleged anomalies of decision and inference," Topoi, Vol 30 No 1, pp.59-69. 10.1007/s11245-010-9084-1. 
Shen, L., Lu, W., Peng, Y. and Jiang, S. (2012), 'Critical assessment indicators for measuring benefits of rural infrastructure investment in China', Journal of Infrastructure Systems, Vol 17 No 4, pp.176-183. 10.3969/j.issn.1002-6819.2010.09.001. Sherwin, D. (2006), 'Reducing the cost of green', Journal of Green Building, Vol 1 No 1, pp.47- 54. 10.3992/jgb.1.1.46.

Shi, Q., Yan, Y., Zuo, J. and Yu, T. (2016), 'Objective conflicts in green projects: a critical analysis", Building and Environment, Vol 96, pp.107-117. 10.1016/j.buildenv.2015.11.016.

Sourani, A. and Sohail, M. (2015), "The Delphi method: review and use in construction management research.' International Journal of Construction Education and Research, Vol 11 No 1, pp.54-76, 10.1080/15578771.2014.917132.

Steiner, J., Stewart, C. (2016), 'Perceiving prospects properly', American Economic Review Vol 106, No 7, pp.1601-1631.https://www.aeaweb.org/issues/419.(accessed 22 October, 2020)

Sun, C., Chen, Y., Wang, R., Lo, S., Yau, J. and Wu, Y. (2019), 'Construction cost of green building certified residence: a case study in Taiwan', Sustainability, Vol 11, No 2195, pp.1-10. 10.3390/su11082195.

Suh, M.J., Pearce, A.R., Song, Y., Kwak, Y.H., Kim, J. and Zhang, Y. (2019), ' The impact of LEED-energy star certified office buildings on the market value of adjoining buildings in New York City.'” Journal of Green Building, Vol 14 No 1, pp.32-51. 10.3992/19434618.14.1.31.

SBMS (2019), 'Sustainable buildings market study." RAMBOLL, Bright Ideas. Sustainable change. Denmark. https://ramboll.com/media/rgr/sustainable-buildings-becoming(accessed 22 October 2020)

Syphers, G., Baum, M., Bouton, D. and Sullens, W. (2003), "'Managing the Cost of Green Buildings', State of California Sustainable Building Task Force, State of California Consumer Services Agency. http://www3.cec.org/islandora$\mathrm{gb} / \mathrm{fr} /$ islandora/object/islandora\%3A1010

Taemthong, W. and Chaisaard, N. (2019), "an analysis of green building costs using a minimum costs concept', Journal of Green Building, Vol 14 No 1, pp.53-77. $\underline{10.3992 / 1943-4618.14 .1 .53}$

Tierney, G. and Tennant, S. (2015), 'House building in Scotland: the sustainability performance gap", In: Raidén, A.B. and Aboagye-Nimo, E. (Eds) Proceedings $31^{\text {st }}$ Annual ARCOM Conference, 7-9 September 2015, Lincoln, UK, Association of Researchers in Construction Management, pp.317-326.

World Green Building Trend (WGBT). (2018), 'Business case of green.' World Green Building Council, USA

World Green Building Council (WGBC) (2016), 'the business case for green building'. https://www.worldgbc.org/news-media/business-case-green-buildingreview-costs-andbenefits-developers-investors-and-occupants. (Retrieved $15 \quad$ June 2019).

Yudollahi, M., Mirghasemi, M., Zin, R. M. and Singh, B. (2014), 'Architect critical challenges as a project manager in construction projects: a case study', Advances in Civil Engineering, 2014, 1-16, doi.org/10.1155/2014/205310.

Zahoor, H. Chan, APC., Gao, R. Utama, WP. (2017), 'The factors contributing to construction accidents in Pakistan: their prioritization using the Delphi technique', Engineering, 
Construction and Architectural Management, Vol 24 No 3, 10.1108/ECAM-01-20160027

Zhang, S., Fu, Y. and Kang, F. (2018), 'How to foster contractors' cooperative behaviour in the Chinese construction industry: direct and interaction effects of power and contract", International Journal of Project Management, Vol 36, pp.940- 953. 10.1016/j.ijproman.2018.05.004

Zhou, L. and Lowe, D. J. (2003), 'Economic Challenge of Sustainable Construction', In: Proceedings of the RICS Construction and Building Research Conference, School of Engineering and the Built Environment, University of Wolverhampton, UK,1-2 September, Edited by D. Proverbs, ISBN 1R84219R148R9, RICS Foundation, pp.113- 126.

$10.1080 / 096132100418465$ 

